\title{
Emotional Intelligence as a Vital Indicator of Teacher Effectiveness
}

\author{
Gulseren Sekreter ${ }^{1}$
}

\author{
${ }^{1}$ Faculty of Education, Department of Mathematics, International Tshik University, Erbil, Iraq \\ Correspondence: Gulseren Sekreter, International Tshik University, Erbil, Iraq. \\ Email: aksekreter@hotmail.com
}

Received: January 17, 2019

Accepted: February 24, 2019

Online Published: March 1, 2019

doi: 10.23918/ijsses.v5i3p286

\begin{abstract}
The present research will refer to emotional intelligence (EI) with important work-related outcomes such as teacher performance as well as organizational productivity. The initial goal is to explore the effect (role) of emotional intelligence skills in effective teaching, and its effect on the productivity of teacher's performance during the teaching-learning process. Effective teaching and good learning are two integral parts of students' academic success. There are number of crucial factors which play an important role in teacher effectiveness such as teacher's classroom management skills, teacher's subject expertise, knowledge of teaching methods, teacher's professionalism, - how to structure, explain and present the materials, and others. But emotional intelligence (EI), as the fifth component and the most important factor, sets most effective teachers apart from the majority because process of learning involves emotional and intellectual endeavor, struggle, frustration, excitement, also anxiety. Therefore an affective teacher needs an understanding of students' emotional state and causes of their behavior to create an ideal learning environment that encourages positive social interaction, active engagement and strong motivation to learn. In the light of exploration of the role of Emotional Intelligence in effective teaching-learning process, this study asserts that teachers' emotional competence factors contribute to the teacher effectiveness more than any other single factor. For instance, development of supportive teacher-student relationships, effective classroom management strategies, and successful emotional learning program implementation in order to create an ideal classroom climate that is more conducive to learning. All these contributions promote positive developmental outcomes in students' achievements.
\end{abstract}

Keywords: Emotional Intelligence, Teacher Effectiveness, Student's Achievement

\section{Introduction}

Although the absence of emotional illness, neurotic or psychotic behavior is the first step towards personal growth and full-functioning at the basic level, it is not sufficient to qualify one as a healthy personality and to operate effectively in life. (Schultz, 1997). In order to define a healthy, self-actualized individual, Salovey and Mayer (1990) state that "people who have developed skills related to emotional intelligence understand and express their own emotions, recognize emotions in others, regulate affect, and use moods and emotions to motivate adaptive behaviors. In order to build a healthy personality in students, teachers' main concern should not be only enhancing academic success but also social progress of all students. MacMullin (1994) found that students' social and emotional imbalances i.e. anxiety, frustrations, tensions etc. is the prominent obstacle in the way of achievements among students. Unless emotional growth and social skilling take place, students will not be able to operate effectively in life. Therefore, awareness of how important maintaining a student's emotional health and social skilling is the most important factor 
for being an effective teacher. It seems reasonable to say that to develop students' emotional intelligence skills, teachers must be educated in this field as well. Because teacher is a role model for students on how to regulate their emotions appropriately in the classroom. Additionally, teacher with high emotional intelligence use more positive, well-adapted coping strategies when dealing with different sources of stress at school, and they feel greater satisfaction with their work. Thus, the emotional intelligence of a teacher is the most important contribution to the effectiveness of a teacher.

Some people have better psychological well-being than others, and they are more likely to be successful in life. There is a growing body of evidence indicating that stress adversely affects performance, productivity, job satisfaction, personal health, and the general quality of life. A teacher has to play different roles in his/her institution and face numerous difficulties, such as conflicts with administration, low payment, relationship with parents, lack of discipline and motivation among learners, numerous decisionmaking issue, additional duties, much paper-pencil work, and others. Therefore teaching profession has been viewed as a high stress area and identified by psychological researchers as requiring a high level of emotional intelligence for career success and job satisfaction. However, is the emotional intelligence a certain inborn characteristic like IQ that predispose people to become a teacher? There certainly are "emotionally intelligent born" teachers, but the good news emotional intelligence is not stable it can be trained and improved. Consequently, to reduce occupational stress and increase teacher effectiveness the intentional inclusion and development of emotional intelligence skills among prospective teachers is a necessity. Thus, the high goals and expectations of education in the 21 st century will be achieved.

\section{Literature Review}

\subsection{What is Emotional Intelligence (EI) and Why Does It Matter?}

Goleman defined emotional intelligence or EQ (emotional quotient) as the capacity for recognizing our own feelings (self-awareness) and those of others (empathy), for motivating ourselves (motivation), and for managing emotions well in ourselves (self-regulation) and in our relationships (social skills) (Goleman, 1998). Goleman sees emotional quotient as non-traditional views of intelligence. In his view Emotional Intelligence involves an ongoing process of development and it does not represent an unchanged state of being, but requires an ongoing commitment to growth and continued personal development (Goleman 1996). For this reason Emotional Intelligence and continuous learning and growth assist a teacher with effective performance. "The reason we don't get people's full potential is emotional incompetence" (Goleman, 1998).

According to Goleman (1996), people differ in terms of the capacity for recognizing their own feelings and those of others, for motivating themselves, for managing emotions well in themselves and in their relationships. Similarly, they differ in their ability to understand what other people are feeling and why, and their ability to influence or manage the feelings of others. Emotional intelligence describes these individual differences. Goleman indicates that these differences play bigger role than cognitive intelligent in determining success in life and in the workshop for individuals. In other words, distinguishing thing the outstanding performance from the poor one is the level of emotional intelligence. The importance of cognitive intelligence is deniable (measured through IQ test: a measure of intellectual function), and precisely we never ignore the necessity of either being able to organize instructions, management skills or 
providing relevant assessment and righteous evaluations. They are indisputably important, but our emotional awareness and ability to control feelings by using EQ rather than by our IQ can be powerful and at times more powerful than IQ and can determine our success. IQ defines how smart you are while Emotional intelligence EQ., defines to what extent how well you use your smartness. As a result, EQ level sets successful individuals apart from others. The good news is that while IQ stable which cannot be chanced much, EQ can be improved.

From another perspective EQ "is a balance between heart (emotions) and mind (intelligence). If a person only uses the advantage of cognitive skills, then he can act like a robot, which is controversial with human life. If a person lets emotions to control his actions, then he is unable to use his mindfulness. If a person able to acknowledge and guide emotions consciously and constructively then intellectual performance can be enhanced (Sharma \& Bindal, 2012)

\subsection{The Concept of Emotional Intelligence}

Bar-On's (1997) definition of emotional intelligence incorporates a broad array of constructs which are named as emotional, personal and social abilities. The Bar-On model provides the theoretical basis for the EQ and according to him (1997) emotional intelligence refers to an array of non-cognitive abilities, competencies and skills that determine how effectively we understand and express ourselves, understand others and relate with them and one's ability to cope with daily demands and environmental pressures. Bar-On's emotional-social intelligence construct include five main areas of competencies and fifteen subscales which will contribute to emotional intelligence (Bar-On, 2006).

Also Daniel Goleman has helped to develop an expanded view of emotional intelligence based on Salovey and Mayer's (1990) theory. Goleman identified the five 'domains' of EQ as: three domains comprise self-awareness, self-regulation, and motivation that describe personal competencies, that is, knowing and managing emotions in oneself. Two dimensions comprise empathy and social skills that describe social competencies, that is, knowing and managing emotions in others. His construct of emotional intelligence as the abilities for recognizing our feelings and those of others, for motivating ourselves and being persistent in the face of frustrations, for managing emotions well in ourselves and in our relationships. He emphasizes that principles of emotional intelligence provide a new way to understand and assess people's behaviors, management styles, attitudes, interpersonal skills, and potential. Therefore it is necessary for developing people.

\subsection{Teacher's Emotional Intelligence is the Invisible Part of an Iceberg}

There are so many factors influencing the quality of education as well as teaching and learning process, some of them are: socio-economic factors, good curriculum and syllabus, planning and management skills, quality and amount of educational resources (on-paper, technical), teaching and learning methods and strategies, time spent on teaching and learning, teacher/student ratio (number of students in a group), qualification and experience of teacher, teacher flexibility (ability to make quick optimal decisions), caring, personal peculiarities of teacher and students etc. In the light of researches, however, physical environment did not play such a significant role in the improvement of student's achievement as teacher relations did. Money and materials cannot buy an ideal learning environment only teacher can provide that 
environment. When teacher pay more attention to students and show more concern for their well-being, confidence, and supportiveness in learning process, both student's performance and achievement increase. Educators consistently claimed that teacher effectiveness is the single biggest contributor to student achievement. Therefore effective teaching and good learning are two integral parts of students' academic success. There are number of crucial factors which play an important role in teacher effectiveness such as teacher's classroom management skills, teacher's subject expertise, knowledge of teaching methods, teacher's professionalism, - how to structure, explain and present the materials, and others. But emotional intelligence (EI), as the fifth component and the most important factor, sets most effective teachers apart from the majority. Because process of learning can involve emotional and intellectual endeavor, struggle, frustration, excitement, also anxiety in any context. Emotions of learners have an effect on their learning. Unfortunately, in many of today's classrooms because of teacher's lack of emotional competences the atmosphere is not conducive to learning. Most of the teachers ignore the fact that when learners faced with frustration, worry, or anxiety they lose access to their own background knowledge, and the capacity for reasoning and to make connections. In many of today's classrooms, we see children whose intellectual energies and capacities are drained by negative emotional states. Emotion is the on / off switch for learning." Teacher has a significant role to play in shaping positive emotions. Therefore an effective teacher needs an understanding of students' emotional state and the causes of their behavior. Thus he/she can create an ideal learning environment that encourages positive social interaction, active engagement and strong motivation to learn.

At the University of Limerick students were asked to explain their nomination of a lecturer for a teaching award. Sarah Moore and Nyiel Kuol analyzed these responses and found that: "students often refer to emotions, emotional states and emotionally satisfying experiences when providing descriptions of excellent teaching and generally seem to associate their own and their teachers' emotional states with good teaching and good learning" (Moore and Kuol, 2007, p.87). From this analysis it is clear that teachers who are emotionally intelligent are also more likely to be efficient in their teaching-learning process and achieve their professional goals successfully.

The 21 st century has been offering much better conditions in every aspect of life than the previous centuries. Especially educational conditions financially and technologically are now at higher level when compared with the previous centuries. In addition, Goleman (1998) in his book "Working with emotional Intelligence" states that IQ is about 24 points higher now than in 1918 due to some factors such as better nutrition, more schools, smaller family size, etc. However, EI indicators are coming down compared to the last generation and its negative effects has been seen. Nowadays children are more reluctant, depressed and, more lonely and angry, more prone to worry, and more aggressive. Similarly, Gottman (1997), in his book " Raising an emotionally Intelligent Child" indicates that "from the mid 1970's to the late 1980's, according to parents and teachers rate, children have become more short-tempered, more cranky, more depressed and lonely, more reckless and disobedient. But the question is why kids face these negative experiences? There are many possible reasons under this problem such as more TV watching and computer game playing and having less free-time with parents due to long working hours, less relative connection in a family. In such an environment children cannot have a chance to increase their EI capacity. Because EI can be developed through social life. Even if this century offers better conditions than previous centuries, however, social life has been dramatically decreasing in the last decades. It is important to state 
that children with high EI are able to perceive and regulate their emotional states which is vital in selfcontrolling mechanism, motivate themselves better and they are better at a social life.

In the 1900s the traditional definitions of intelligence emphasized IQ (cognitive aspects such as analytic thinking, memory) to distinguish outstanding performance of individuals. However, some influential researchers in this field of study had begun to recognize the importance of the non-cognitive aspect (EI) as well. Therefore exploration of the role of Emotional Intelligence in effective teaching-learning process has aggravated interest in many researchers throughout the world, and resulted in rather challenging findings which ultimately led to development of training programs that taught both.

Nowadays, many people can choose to become a teacher. But the question is whether they will be able to become the effective one. Studies of teacher-effectiveness indicate that being a teacher is not an easy going job and being an effective teacher is more complicated and difficult than many people think. Unlike this reality, it has been accepted as the easiest manageable job among the others. One of the most important reason to think like that is that teaching is not among the highest paid jobs in contemporary moneycentered society. Therefore competition to teaching faculties is not too high when compared to law, medical, business, medicine, IT, and so on. Unfortunately, many young people who even never try to become a teacher or some who do not care about this job choose to become a teacher as their last resort. It is obvious to say that such "teachers" will ruin many souls, and lots of potential will be lost for the country as long as we don't understand the importance of teaching profession for the society. We cannot ignore the fact that teachers are at the core of society building and education quality in a society has strong impact on development goals. The immediate and clear implication can be done more to increase education quality by improving the effectiveness of teachers than by any other single factor. In addition to educational researchers consistently state that most important factor affecting student learning is the teacher and an effective teacher has a great potential to affect student's educational outcomes. As it is mentioned before a teacher has to play different roles in his/her institution and face numerous difficulties ( conflicts with administration, low payment, relationship with parents, lack of discipline and motivation among learners, numerous decision-making issue etc.). Therefore the teaching profession has been viewed as a high-stress area and identified by psychological researchers as demanding a high level of emotional intelligence for career success and job satisfaction. Consequently, to reduce occupational stress and increase teacher effectiveness the intentional inclusion and development of emotional intelligence skills among prospective teachers is a necessity in order to reach high standard. Because, while content knowledge is important and necessary, it alone cannot determine whether the teacher is able to teach effectively so that students learn. As a teacher, you are expected to deal with learners of different backgrounds of emotional states and with a variety of individual differences at different age levels to provide emotional and intellectual growth of your students. This is important in order to provide effective teaching and guidance. According to Sharma and Bindal (2012, p.137), "an effective teacher must not only be a master of his or her subject matter, but can understand his students well and transacts the curriculum as per the needs and interests of his students". In terms of educational organization, the teacher's emotional intelligence is the key not only for the organization but it also helps in the development of individuals' emotional intelligence. In order to reach high goals and expectations as teachers, our main goal is to enhance both academic and emotional progress of all students. 


\subsection{Determining Crucial Factors of Emotional Intelligence in Teacher Effectiveness}

As it is indicated before, being an effective teacher does not only mean having deep content knowledge or organizational skills. Teacher's ability to communicate effectively becomes more critical than their technical, organizational skills and capabilities (Kauts \& Saroj, 2010). On the other hand emotional intelligence of teacher's, plays a significant role in that school organization's "decision making, leadership, strategic and technical breakthrough, open and honest communication, trusting relations and teamwork, custom, commitment and creativity as well as innovation" (Cooper, 1997, p.33). For an effective teacher student engagement in learning, creating a friendly classroom environment, promoting enthusiasm, being passionate about their ideas, learning and their relations with students (Sharma \& Bindal 2012), and motivating them to enhance learning are always foremost factors in education.

However, the difficulties on the way of being an effective teacher need to be considered, as well. A teacher has to face innumerable challenges and play different roles in his/her institution. Conflicts with administration, low payment (especially, for beginner teachers), relationships with parents, lack of discipline and motivation among learners, teacher stress linked with a lot of decision making, additional duties, much paper work, etc. He/she not only plan lessons but also organize activities, maintain necessary records, make purchases, administer time-table, oral and aural teaching aids, adopt new techniques of communication and motivate the students by words and deeds. Thus, teacher is expected to possess a multifaceted personality. In spite of these difficulties teachers have to show optimal potential. . Under these circumstances, it is but normal result that teachers will remain under stress which is sure to affect their effectiveness negatively while teaching. The amount and degree of stress a teacher experiences may be related to his negative self-perception, negative life experiences, low morale, and the struggle to maintain personal values and standards in the classroom (Worrall \& May, 1989). In a study carried out with secondary teachers in England, it was observed that the teacher's emotional intelligence predicts level of burnout (Brackett, Palomera \& Mojsa, 2010). Gawali (2012, p. 5) sate that "burnout (teachers who are too tired, physically, mentally and emotionally exhausted of their jobs) has been shown to have negative repercussions not only to the teacher's well-being but also on the teaching-learning processes in which he or she is immersed". Also prior studies show that burnout negatively influences student performance and quality of teaching (Vanderberghe \& Huberman, 1999) and negatively affects interpersonal relations between student and teacher (Yoon, 2002). According to Sutton and Whitely (2003), emotional intelligence of teachers is necessary, both for their well-being and effectiveness and quality in carrying out teaching-learning processes in the classroom in general, and in particular, for the socio-emotion development of students.

Highly emotionally intelligent teachers appear to experience significantly less stress at work than less emotionally intelligent counterparts. Because their adequate physical and psychological well-being help them to demonstrate higher in-role job performance . Kauts and Saroj (2010) have made a study which is based on the assumption that application of emotional intelligence can increase teacher effectiveness and reduce occupational stress among teachers at secondary school stage. Six hundred secondary school teachers have been selected as a sample for the study. After analysis they founded that teachers with high emotional intelligence were having less occupational stress and more teacher effectiveness, whereas, teachers with low emotional intelligence were having more occupational stress and less teacher effectiveness. Thus, emotional intelligence was found to be helpful in reducing occupational stress of 
teachers and enhancing their effectiveness in teaching. Consequently, teachers with high emotional intelligence use more positive, well-adapted coping strategies when dealing with different sources of stress at school, and they feel greater satisfaction with their work (Brackett, Palomera \& Mojsa, 2010). Goleman similarly states that a person does not get his full potential unless he includes his own emotional competences to his job (Goleman, 1998).

\subsection{An Effective Teacher Framework Based on Emotional Intelligence}

This section describes how teachers can create a more suitable climate for learning and emotionally safe learning environment based on emotional intelligence. I summed up the reviewed literature as follows:

1. Self-awareness: With this attribute teachers recognize their own emotions, how they affect their thoughts and behavior, and know their strengths and weaknesses. Unless they evaluate their emotions, they cannot manage them.

a. Self-regard: Teachers with positive self-regard competence:

- $\quad$ are self-motivated to learn and communicate effectively with students. When teachers have high regards for themselves, they will be high achievers academically, fulfilled and satisfied by themselves.

b. Emotional self-awareness: Teachers with this competence:

- aware their own emotions and how their emotions affect their and students performance.

c. Accurate self-assessment: Teachers with this competence:

- know their strengths and limitations,

- want to receive new perspective and feedback from his students, parents and colleagues.

- motivated by continuous learning.

d. Self-actualization: Teachers with this competence:

- persistently try to strive their optimal growth, and development,

- try to improve oneself in every aspects of life.

e. Self-confidence (assertiveness): Teachers with this competence:

- are self-confident about their teaching capabilities.

- acknowledging that they are the best for the teaching profession,

- accept and express their feelings e.g. frustration, anger, tension without being aggressive or abusive.

- conveying their ideas and opinions in a healthy, non-defensive, and non-insistent way.

- have a positive impact on others

- are able to create a positive cycle in relationships by encouraging them to respond assertively.

- they are able to outwardly express their beliefs and thoughts,

- enable to earn respect from students.

f. Independence: Teachers with this competence:

- are able to exploit their professional skills autonomously and develop learners' autonomy.

- have autonomous learners who recognize that they are responsible for their own learning.

2. Self-regulation: Teachers with this competence:

- Have the ability to controll their negative feelings and impulsive behaviors as well as manage their emotions in healthy ways. 
a. Self-control:

1. Stress tolerance: Teachers with this competence:

- manage impulsive feelings and distressing emotions well among students

- think clearly and stay focused under pressure of school demands

- are able to endure adverse events and stressful situations without losing control, and positively coping with stress and increase their effectiveness despite difficulties.

- are resourceful and effective to successfully overcome the specific problem at hand.

- are able to come up with suitable methods, and knowing what to do, when to do and how to do in classroom management strategies.

- show an optimistic disposition in every aspect of job conditions.

2. Impulse control: Teachers who possess this competence:

- rarely become impatient, overact or lose control in communication with students.

- display predictable behavior

- $\quad$ are generally calm, rarely impulsive, and work well under pressure.

b. Trustworthiness: Teachers with this competence:

- have strong moral principles and behave ethically towards his/her students

- maintain the quality of integrity

- build trust through reliability and authenticity among students

- accept their own mistakes and confront unethical actions towards students

c. Honesty: Teachers with this competence:

- feel accountable for personal performance.

- meet educational commitments and keep promises

- hold themselves accountable for meeting their educational objectives

- have self-discipline in their teaching profession

d. Adaptability: Teachers who possess high levels of adaptability

- can make a substantial contribution in the school organization.

- flexible, and competent at providing adequate solutions in any decision making process.

1. Reality testing: Teachers with this competence:

- are realistic and effective in understanding problems,

- set reasonable and doable learning goals for their students.

2. Flexibility: Teachers who function flexibly:

- are able to adjust their emotions, thoughts, and behavior to change situations and conditions.

- ability to deal with problematic situations, adapt to unfamiliar, unpredictable, and dynamic classroom circumstances.

- are able to cope with environmental (school, parents and students) demands by effectively

- are able to change their minds when they are mistaken, and open to different ideas, ways, and practices (pragmatic approach).

3. Problem-Solving: Teachers with this competence:

- can easily find good ways of dealing with everyday difficulties and handling multiple demands.

e. Innovativeness: Teachers with this competence:

- to increase their teaching skill they seek out new ideas from a wide variety of sources 
- provide original solutions to classroom's problems

- have new ways of teaching that promote student engagement and different pedagogical approaches, course design and organization, and assessments to increase students achievement.

3. Motivation: Teachers who function well in this area remain optimistic and continue striving in the face of setbacks, barriers, and failure situations.

a. Achievement drive: Teachers with this competence:

- strive to improve or meet a standard of excellence in their profession.

- they have high-drive to meet their objectives and standards in students' academic achievement.

- consistently work toward their educational goals.

b. Commitment: Teachers with this competence are:

- have extremely high standards for the quality of their work.

- For the sake of well-being of their sacrifices to meet their objectives, standards in their teaching profession.

- actively seek out opportunities to accomplish the learners' better learning.

c. Initiative: Teachers with this competence:

- stimulate learners through emotional energy (by changing their negative thoughts into positive one).

- $\quad$ are ready to seize opportunities to make themselves more effective.

- persist on their instructional goals beyond what is required or expected from them.

d. Optimism: Teachers who function well in this area:

- despite obstacles, setbacks, and barriers of the educational process they operate from the hope of success rather than fear of failure

- have the ability to look at the brighter side of life

- have the ability to maintain a positive attitude, even in the face of adversity

4. Empathy: Teachers who function well in this skill are able to sympathize with their students by putting themselves in the students' shoes and give helpful feedback. Empathic teachers are well tuned to the emotions of their students and are able to pick up on what is going on in the classroom.

a. Social Awareness: Teachers with this competence:

- are attentive to emotional cues of students (constantly picking up emotional cues) and accurately understand unspoken or partly expressed thoughts, feelings, and concerns of students.

- $\quad$ show sensitivity and understanding students' viewpoint and listen them well.

b. Helping out for orientation: Teachers with this competence are:

- anticipating, recognizing, and meeting students' needs

- seek ways to increase students' adaptation and satisfaction

- act as a trusted advisor whenever students need.

c. Developing students' abilities: Sensing what students need in order to be more successful, and bolstering their abilities. Teachers with this competence:

- acknowledge and reward students' strengths, accomplishments, and development

- propose useful feedback and identify students' needs for development 
- Mentor, give timely coaching, and offer assignments that challenge and grow students' abilities.

d. Leveraging diversity: Cultivating opportunities through student diversity. Teachers with this competence are:

- respect and relate well to students from varied backgrounds

- $\quad$ sensitive to students intellectual and characteristics differences

- see students diversity as opportunity, creating an environment where diverse people can thrive

e. Organizational Awareness: Understanding the "power" relationship in student's own group or organization. Identifying the real decision makers and who can influence them. Recognizing the values and cultures of classroom organization and how they affect the way students' behave. Reading a group's emotional currents and power relationships. Teachers with this competence are:

- accurately read key power relationships among students.

- detect crucial social networks among students.

- understand the forces that shape views and actions of students.

5. Social skills: Teachers who function well in this area:

- have the ability to get along with students, parents, school administration and their colleagues as well as to establish positive relationships .

- utilize effective tactics for persuasion.

- use fine-tune presentations to attract attention of learners.

- use complex strategies like indirect influence to build consensus and support in their relations

a. Effective Communication : Teachers with this competence are:

- send clear and convincing messages to the collaborators (e.g. students, parents, colleagues and school administration )

- dealing with difficult issues in classroom management effectively.

- listen well, seek mutual understanding while communicating with students in teachinglearning process.

1. Social responsibility: Teachers who possess this skill:

- have the ability to act in a co-operative, contributory and constructive manner towards students and other partners.

- act in a socially responsible manner, even though one may not benefit personally.

- they possess social consciousness and a basic concern for students and their achievement. (unique attribute for the socially responsible people).

- possess good sense of social responsibility are often described dependable.

- A teacher with this competence is able to promote a friendly, cooperative climate in his/her class.

2. Interpersonal relations: Teachers with this skill show positive interpersonal relationship skills which involve:

- the ability to establish and maintain mutually satisfying relationships.

- the ability to give and receive warmth and affection and to convey sincerity to another human being, 
- desirability for building up friendly relations with students and other partners.

- the ability to feel at ease and comfortable in their relations

- the ability to possess positive expectations concerning teaching-learning process and social relationship.

b. Instead manager play a leader role: Teachers with this competence not try to manage classroom they play a leader role which means:

- inspire and guide students.

- make a difference and create a positive chance.

- articulate and arouse enthusiasm for effective teaching

- guide the performance of students while holding them accountable

- in every aspect of education process lead by example

c. Effective conflict resolution: Teachers with this competence:

negotiating and resolving disagreements in the classroom.

handle difficult students and tense situations with ethically and tact in classroom management.

d. Collaboration and cooperation: Collaborative working with partners toward shared educational goals. Teachers with this competence :

- balance a focus on task with attention to relationships

- Collaborate, share plans, information, and resources for mutual benefit.

- Promote a friendly, cooperative ideal learning climate

- recognize and enlarge opportunities for collaboration

e. Learners team capabilities: Teachers with this competence :

- Create group synergy in pursuing collective goals among learners.

- Model team qualities like respect, helpfulness, and cooperation

- Draw all learners into active and enthusiastic participation during teaching-learning process.

\section{Conclusion}

Findings of the study show that teacher's EI capacity is the vital indicator for his her effectiveness. Teacher who pays more attention to students and show more concern for students' well-being, confidence, and exhibits supportiveness in learning process, both student's performance and achievement increase. It's also essential for teachers to understand the fact that social skilling appears in their performance and it plays a critical role for the well-being of the student and the institution. Thus, a positive affective display in student interactions (smiling and conveying friendliness) are positively associated with important student outcomes (Figure 1). This role makes a teacher real effective in the classroom activities and help to control their feelings to fulfill the goals and expectations in learning process. 


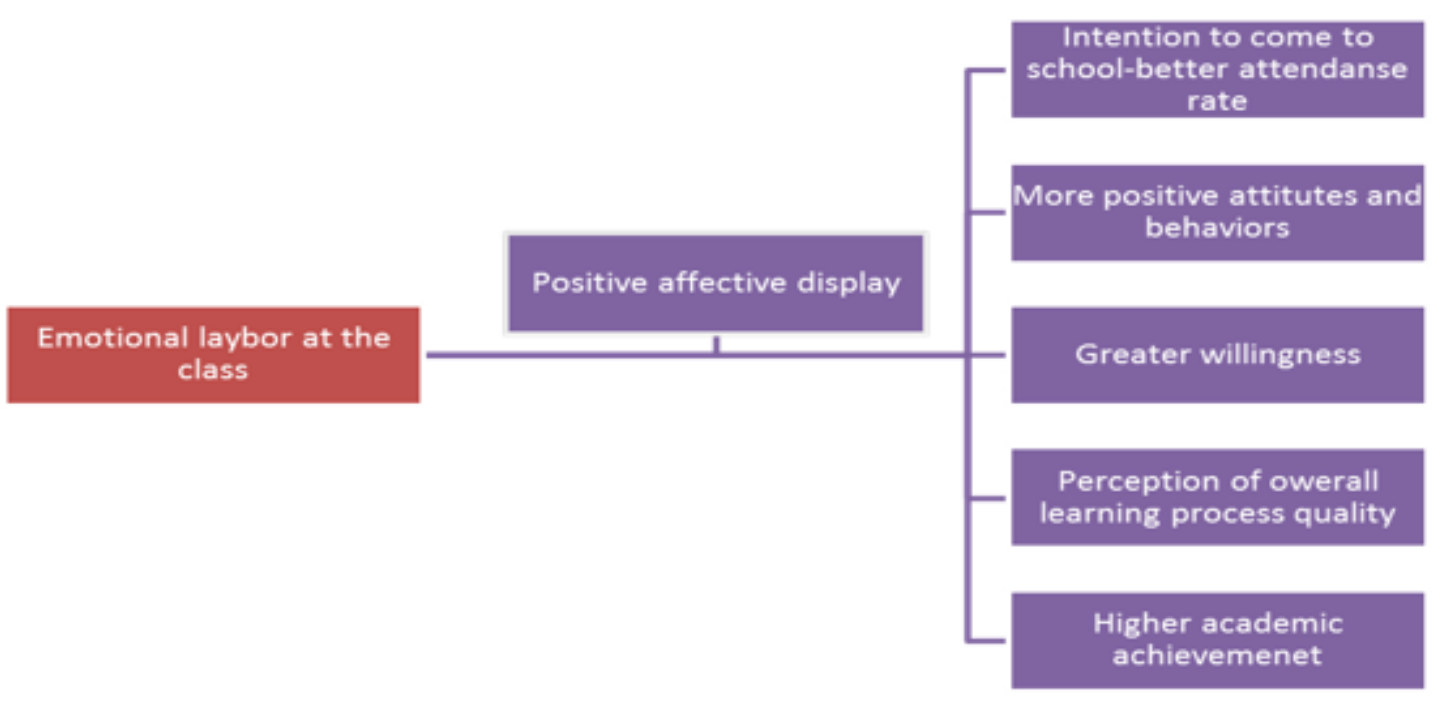

Figure 1: Connection of Emotional Labor and Student Achievement.

From a practical viewpoint, a teacher either expresses only positive emotions, or hides or manages negative feelings. Learning process always requires a positive climate in the classroom in order to make it a stimulating learning environment, improve academic achievement and for the well-being of the students. For these reasons, it is important for teachers to create a positive, emotionally safe classroom environment to provide optimal learning conditions for students. To awake positive emotions in students, teachers have to manage or regulate their real feelings and act consciously during learning process.

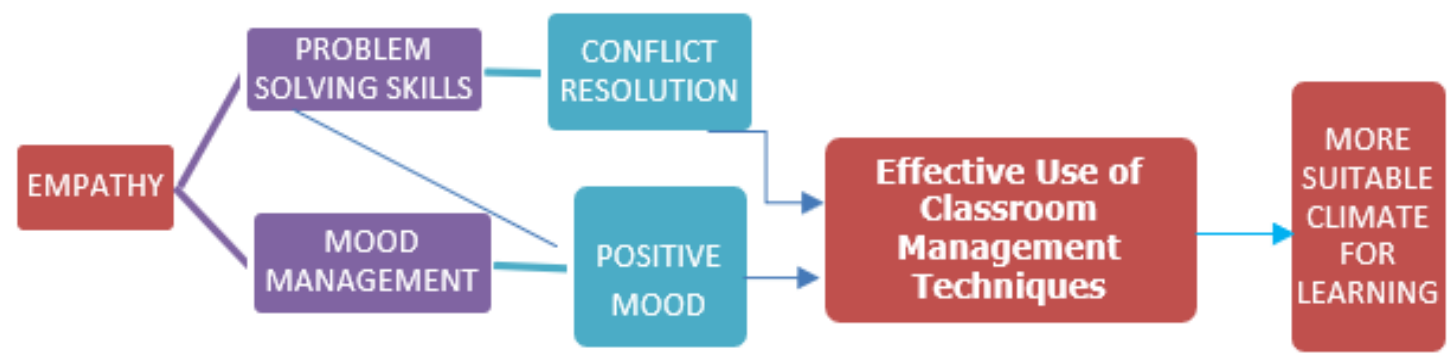

Figure 2: How EQ Provides a More Suitable Climate for Learning

Another finding that makes the present study noteworthy is that there has been identified a definite and direct connection between effective teacher (with high emotional intelligence) and classroom management style. Teacher's emphatic approach (Figure 2) to the situations in a class enhances his problem solving and mood management skills. If you have classroom management problems then your students will certainly have low academic achievement scores. In opposition to this assumption, expert teachers often 
reduce their required efforts in the area of classroom management and spend their energy to be master of subject matter. The real reason of their failure is often not recognized and dully appreciated.

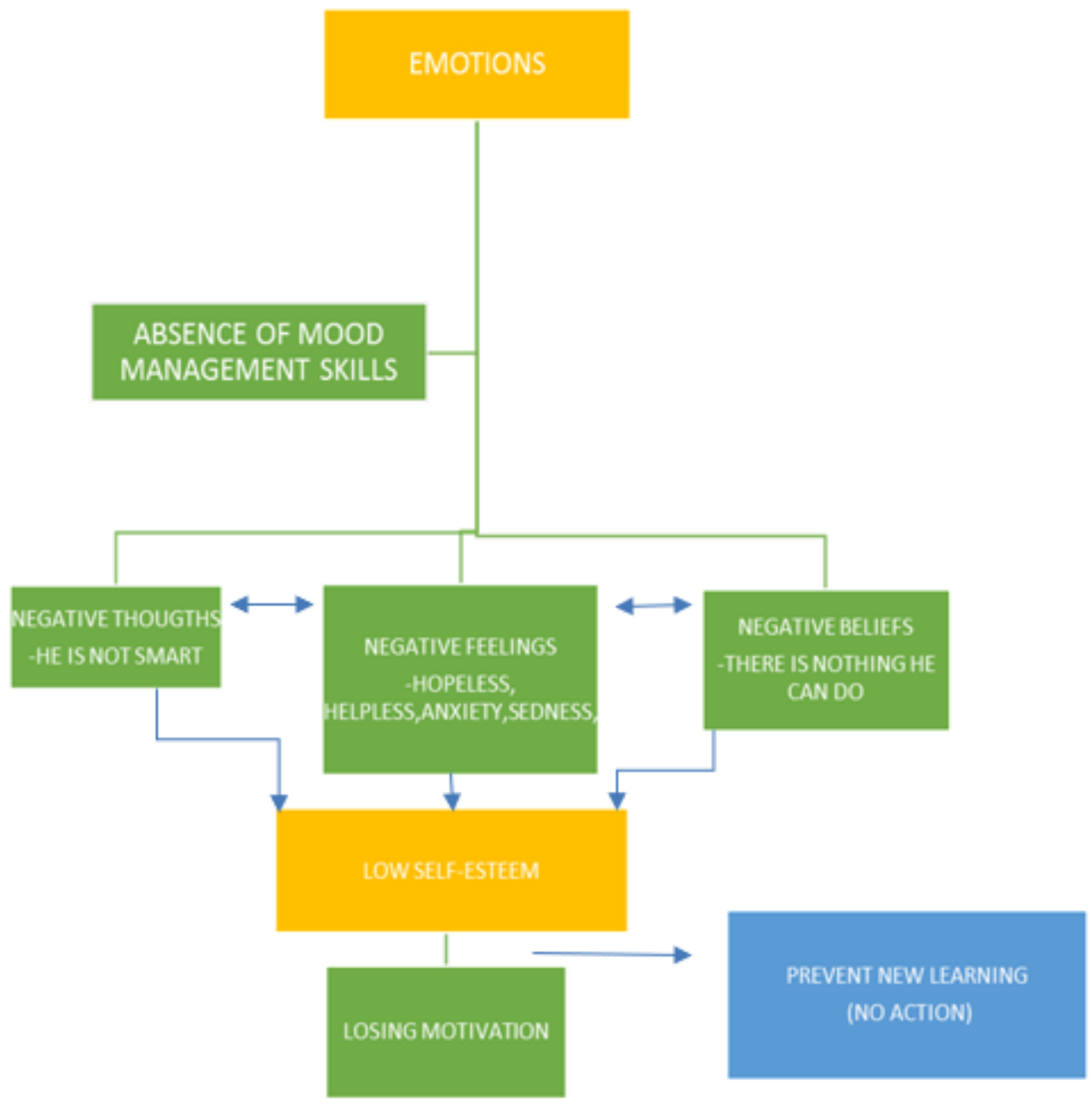

Figure 3: Emotions, Thoughts, Behaviors and their Connection

For instance if a student attributes a failing grade on a math test to the fact that he is not smart, hence, he is using a global (to see the situation as affecting all aspects of life), permanent (to see the situation as unchangeable) and internal (see themselves as the cause) statement about his ability to explain his situation. As a result, he will believe that his lack of intelligence will affect his test scores on all tests in all subjects forever. The worst, there is nothing he can do to change this situation. If the student attributes his poor test score to the fact that the test was really hard, he is explaining his score by specific, temporary and external factors, which can be changed and controlled. He feels sad, but not hopeless. This sort of emotion empowers him, stimulates him to work better. He could study harder or in a different way for the next test and receive a better grade. Consequently, we see that (Figure 3) our thoughts and attitudes play an important role in how we learn to control our emotions and behavior. So is with the students whose emotional intelligence is to be properly brought up and guided by an emotionally intelligent teacher. When students' produce negative thoughts later on negative emotions and beliefs come, therefore: 
- They will have trouble concentrating in schoolwork and can't keep their mind on their work.

- They may think too much about personal problems and focus on the negative thoughts.

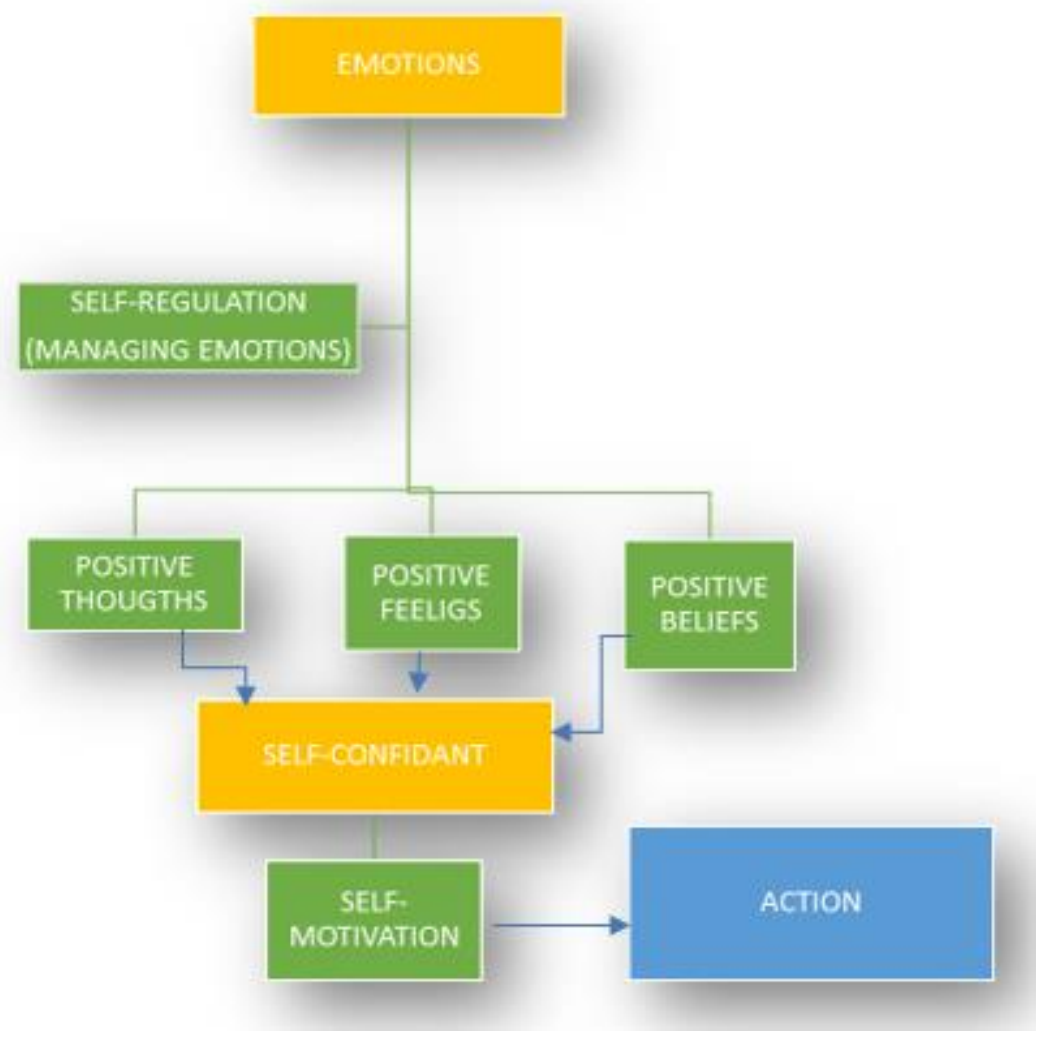

Figure 4: Negative Emotions and their Effect over Learning

As a result their emotions caused their negative thoughts and beliefs because of absence of self-regulation skills

- Finally in both situations, a lack of motivation prevents new learning.

The outstanding role of an effective teacher in this case is to teach students how to regulate their emotions correctly and produce positive thoughts and beliefs. 


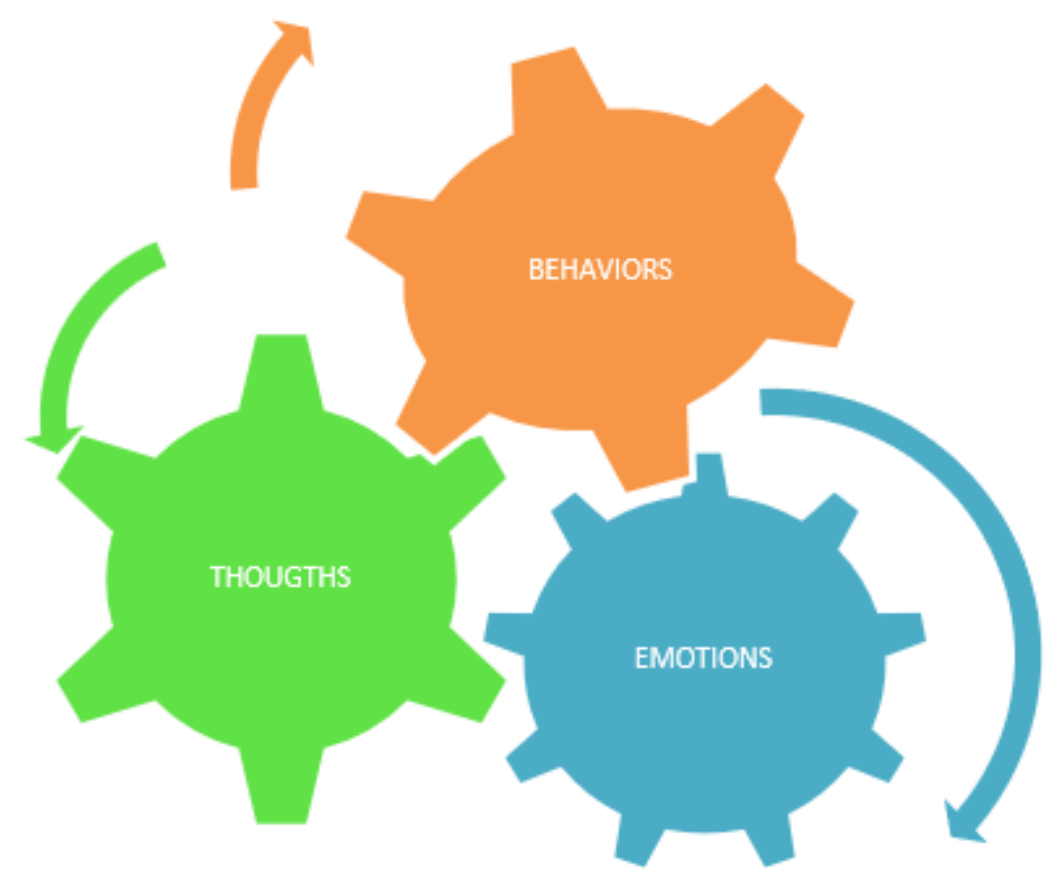

Figure5: Positive Emotions and their Effect over Learning

I personally agree with the assumption that positive emotions in teachers can increase teacher well-being and also the students' level of adjustment. When it is time to take a test, he/she will be more confident that success will come if a more determined action is taken for the test. Strengthening positive thoughts through emotional skills increases student's motivation to study, and pulls him toward his aim of passing the test. Emotions can disrupt thinking and learning. Our current mood influences the way we think, perceive events, remember and make decisions. When we are happy, we have a "clear mind", but when we are upset we can't "think straight". Being optimistic makes us think more positively, be more creative and see and remember neutral events as positive. Positive emotions such as joy, contentment, acceptance, trust and satisfaction can enhance learning. However, extended emotional distress (e.g. anxiety, sadness, tension, frustration etc.) can hamper our ability to learn. These findings of studies are essential to our approach in teaching and fostering motivated and successful learners in the classroom.

It seems clear that emotions can have great important effects on learning and help or hinder the development of a child and their performance and success in school. Also in order to develop students' emotional intelligence skills, teachers must be educated in this field as well. 


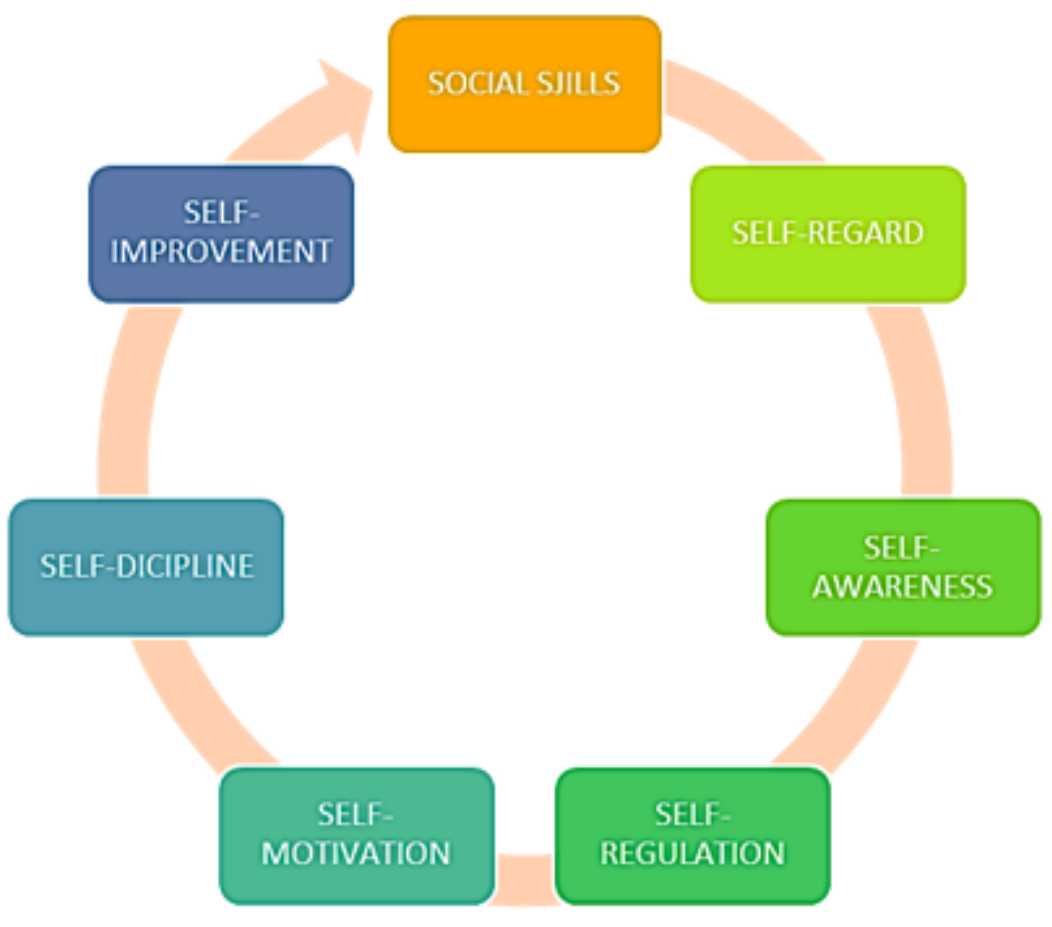

Figure 6: EQ and its Connection with Personal Development

Success in social skills brings to both teachers and students positive emotions and beliefs about themselves which provides them with high self-regard. People should have a positive self-regard in order to be selfmotivated and communicate effectively with people around them. When individuals have high regards for themselves, they will be high achievers academically, fulfilled and satisfied by themselves. Those who have high self-esteem are also great motivators; they motivate themselves and others to greater accomplishments. Therefore the results of this study may produce evidence that the use of teachers' emotional intelligence in the classroom can enhance both teacher and student self-esteem leading to higher achievements.

\section{Recommendations}

In the light of the findings the researcher's private suggestion is that entrance exams for teaching profession should predict EQ level of individuals like IQ level because findings showed that being successful and optimal functioning requires individuals having average level IQ but sufficient level EQ. A low achievement in the entrance exam result may cause highly emotionally intelligent individuals not be admitted because of having a moderate level of IQ, while in reality their IQ is OK, they just could not demonstrate it due to stress. It is also critical to implement effective EQ training into university curricula in order to prepare prospective teachers for thriving teaching careers and successful personal relationships. Another important issue is that, in this century there are rising rates of despair, alienation, drug abuse, crime and violence, bullying, and dropping out of school. These challenges demand from teacher emotional instruction. In order to provide this instruction and develop students' emotional intelligence skills, teachers must be educated in this field as well. It seems reasonable that teachers' lack of the 
possession and use of emotional intelligence skills and strategies may limit the enhancement of students' academic achievement. Thus, emotional intelligence of a teacher contributes to the effectiveness of a teacher.

\section{References}

Bar-On, R. (2006). The Bar-On model of emotional social intelligence (EIS). Psicothema, 18, Supl., 1325.

Bar-On, R. (1997). Bar-On emotional quotient inventory (EQ-i): Technical manual. Canada: Toronto. Multi-Health System.

Brackett, M., Palomera, R., \& Mojsa, J. (2010). Emotion regulation ability, burnout and job satisfaction among secondary school teachers. Psychology in the Schools, 47(4), 406-417.

Cooper, R.K. (1997). Applying emotional intelligence in the workplace. Training and development, 51 (12), 31-38.

Goleman, D. (1996). Emotional Intelligence. London: Bloomsbury Publishing.

Goleman, D. (1998). Working with Emotional Intelligence. New York: Bantam Books.

Gottman, J. (1998). Raising an Emotionally Intelligent Child, Publisher: Prentice Hall \& IBD.

Kauts, A., \& Saroj, R. (2010). Study of teacher effectiveness and occupational stress in relation to emotional intelligence among teachers at secondary stage, 1(1).

MacMullin, C. (1994). The importance of social skills. Paper presented at Rokeby Police Academy, Tasmania. Managerial Issue, 9(3), 257-274.

Moore, S., \& Kuol, N. (2007) Matters of the heart: exploring the emotional dimensions of educational experience in recollected accounts of excellent teaching. International Journal for Academic Development, 12, 87-98.

Salovey, P. \& Mayer, J. D. (1990). Emotional intelligence. Imagination, Cognition, and Personality, 9 , $185-211$.

Schultz, D. (1997). Growth Psychology: Models of the healthy personality. New York: Van Nostrand.

Sharma, V., \& Bindal, S. (2012). Emotional Intelligence - A Predictor of Teacher's Success. International Journal of Social Science \& Interdisciplinary Research, 1(12), 1-9.

Sutton, R.E., \& Wheatley, K. F. (2003). Teachers' Emotions and Teaching: A review of the literature and directions for future research. Educational Psychology Review, 15(4), 327-358.

Vanderberghe, J., \& Huberman, A.M. (Eds). (1999). Understanding and Presenting teacher turnout: A coursebook of International Research \& Practice, Cambridge University Press, Cambridge, U.K.

Worrall, N., \& May, D. S. (1989). Towards a person-in-situation model of teacher stress. British Journal of Educational Psychology, 59, 174-86.

Yoon, J.S. (2002). Teacher characteristics as predictors of teacher-student relationships : Stress, negative affect, and self-efficacy. Social Behavior and Personality. International Journal, 30, 485-493. 